\title{
Increasing natural ventilation using solar chimney
}

\author{
Magdalena Nakielska ${ }^{1, *}$, Krzysztof Pawłowski ${ }^{1}$ \\ ${ }^{1}$ UTP University of Science and Technology in Bydgoszcz, Al. prof. S. Kaliskiego 7, 85-796 \\ Bydgoszcz, Poland
}

\begin{abstract}
At a time when much attention is paid to the problem of energy saving is looking for new technical solutions, among others in the construction industry. At present, searching new solutions is a worldwide trend in creating buildings. Those solutions enable a comfortable use of building structures in harmony with natural environment and ensure reducing energy consumption. Solar chimneys, which facilitate the gravity ventilation by using solar energy, may be a solution to the problem. In hot climates solar chimney has been applied in the process of passive cooling of a building. In temperate zones and cold is used to assist natural ventilation. The problem of the solar chimney is not popular in Poland. Construction in Bydgoszcz two research positions, enabled the analysis of the impact of solar chimneys on the thermal comfort of rooms. This article presents experimental studies on solar chimney located in Poland. The analysis of the flow of air in the room during the day have been measured using two testmodels situated on the 3.1 building of UTP University of Science and Technology at 7 Kaliska street in Bydgoszcz.
\end{abstract}

\section{The introduction}

As the time passes, it can be observed that the price of coal, gas, petroleum and electric energy is constantly increasing. It results in conscious saving based, for example, on thermomodernization of buildings or construction of installation systems that do not consume electric energy, yet create comfortable conditions in rooms.

The climate inside consists of such elements as: the amount of air supplied into a room that has a proper temperature, humidity and cleanness, and maintaining necessary temperature to feel thermal comfort in a room. In order to fulfill those conditions, a heating system and spaces ventilation ought to be designed correctly. Ventilation is a process of removing the internal air from spaces and making room for fresh air which is supplied from the outside [1]. This process can be natural (gravitational) or mechanical. In a gravity ventilation, the natural draught in a vertical ventilation duct causes the flow of air. The air is supplied through the windows and is exhausted through the gravity ducts. The air flow is forced by differential pressure. Air pressure inside is higher than at the outlet of a ventilation duct. The factor that enables the air exchange is density differences between internal and

\footnotetext{
* Corresponding author: magdalena.nakielska@utp.edu.pl
} 
external air. The density of air depends on its temperature. The higher the temperature and the chimney, the higher differential pressure [2], [3].

Unfortunately, in some seasons of the year, a gravity ventilation system does not work in a satisfactory way. High temperatures or high humidity influence on poor working of a natural ventilation in a room and cause the decrease in the quality of microclimate features inside. In order to reduce this problem, many different solutions are adopted to support the operation of a gravity ventilation. Those solutions stimulate the gravity ventilation to work better and, at the same time, improve the microclimate in a room. These are the solutions that do not generate higher costs of facility maintenance, which is of a great importance as far as economic calculation is concerned. At the same time, the facility's demand for the energy does not rise, which is, undoubtedly, an advantage, taking into consideration current legal articles. What is more, energy consumption is connected with carbon dioxide emission into the atmosphere. Currently, the reduction of carbon dioxide emission in the context of power engineering is a priority not only for Poland but also for the whole Europe. The European Union predicts the reduction of carbon dioxide emission by the year 2050 at $80-90 \%$. The EU in its energy package places on member states of EU the duty of $20 \%$ reduction of greenhouse gases until 2020, as one of the elements of climate preservation policy.

Relating to the systems that shape the inner climate in rooms in the summer, current legal articles in "The domestic plan aiming at increasing the number of buildings with low energy consumption" mention exact solutions for eliminating or reducing the power of refrigerating system for air conditioning systems that use refrigerating units. Therefore, what should be done is to:

- limit heat gain (the reduction of solar gain by using sun protection and by the limitation of internal gains),

- adjust air streams to real load,

- use alternative cooling methods (night cooling, the use of ground energy, free cooling and passive cooling).

With reference to the use of alternative cooling methods, the aim of this publication is to present a test stand that is a solar chimney and the analysis of carried out research that confirms justified use of the solar chimney in order to increase the air exchange in a room.

\section{Solar chimney}

Solar chimneys that one can find all over the world differ from one another in construction and materials. The most important external factors that influence the chimneys construction are: the climate, the cardinal points direction, insolation. Despite numerous differences, the chimneys that are being tested have the same elements: air inlet and outlet, glazing and thermal mass.

\subsection{The structure and the principle of operation of a solar chimney}

The components of a solar chimney are presented in the Fig.1. During a day, the sun warms the test stand through the glazing. The additional heat flux supplied to the air, which is exhausted from the room, causes a temperature rise in the duct and, simultaneously, forces warmer air to flow upwards through the outlet. The rise of the difference of air density that is being exhausted between the inlet and outlet results in the enhancement of the "chimney effect". In addition, the energy stored during a day in the walls is released at night. A black colour of thermal mass increases the accumulation of the energy. The energy accumulated at night enables increased velocity of the air flow to be maintained in the duct of a solar 
chimney. It also causes the intensification of the air exchange in the room where the solar chimney is one of the elements of the ventilation system.

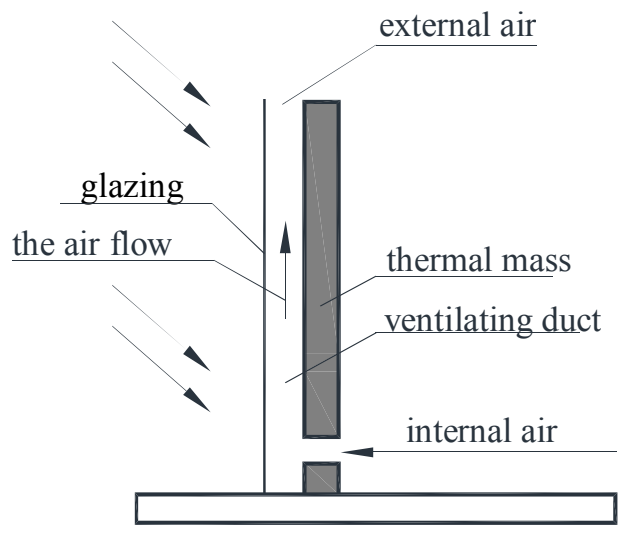

Fig.1. Schematic diagram of solar chimney

The solar chimney as one of the elements of a ventilation system has been known for many years. Along with the technique development, many people have aspired to get to know the phenomena occurring during the working of the chimney. In order to achieve this aim, a lot of seats of learning have begun the research work and used various methods such as: experimental, analytical and computer. R. Khanal and C. Lei [4] present in their article the review of some selected publications on this subject. The tests that dominate in the chosen publications are experimental ones, combined with analytical or numerical. The results of analyses, which are the most similar to real conditions, are obtained by using a test stand. It is usually an expensive and labour-consuming solution. Yet, it allows us to find an optimal solution as regard the height and sectional view of the chimney, the surface of glazing, the angle of inclination and the material that should be used to construct chimneys for specific latitudes and the intensity of solar radiation.

\subsection{The examples of real models of solar chimneys}

The experiment that was carried out by C. Alfonso and A. Olivera [5] makes it possible to broaden the knowledge on justified use of solar chimneys. A test model was made in Porto, in Portugal. The research was conducted by using a tracer gas and then, the results were compared with theoretical values taken from a simulation program. A test object were two identical rooms as regard their geometry. The rooms were made of concrete and were insulated outside. The same solutions were adopted connected with supplying and removing air, yet one chimney was built by means of traditional technology, while there was glazing on the southern wall of the other chimney. The chimneys were made of brick and they were 0.2 meter long, 1 meter wide and 2 meters high. There was also a 5-centimeter insulation on the solar chimney. The heated rooms and chimneys were equipped with measuring apparatus to measure the temperature, the stream of air volume and the velocity of air movement. The temperature outside, wind velocity and wind direction were read from the weather station. All the data were entered into a computer program. Several relations were checked, for example: the influence of solar radiation on ventilation efficiency, the influence of insulation and the height of a chimney on the test results. The conclusion that confirms justified use of solar chimneys is that a solar chimney had a higher 
efficiency at about $10-22 \%$ than a traditional chimney, which is based on average climatic data for Portugal.

At University of Technology in Brno, there were two, full-dimensional solar chimneys built. One of them is of a light structure and the other with thermal mass in order to accumulate the heat. The chimneys are 0.75 meter long, 0.20 meter wide and 2.0 meters high, and have glazing with south exposure at an angle of $30^{\circ}$. P. Charvat, M. Jicha and J. Stetina [6] describe the results of research the aim of which was to test the capacity of solar chimneys in the climate conditions in the Czech Republic. It was found that the flow of air in a solar chimney between 8 a.m. and 6 p.m. was $25 \%$ larger than in a traditional chimney.

\section{Testing the air flow in a solar chimney}

At UTP University of Science and Technology in Bydgoszcz, al. Kaliskiego 7, there are two rooms chosen to modify the existing gravity ventilation system by adding a new element $-\mathrm{a}$ solar chimney. The principle of similarity was dominant in the process of choosing the spaces. Both rooms have close cubic capacity and are situated in the same building, have the same windows and similar number of ventilating ducts. There is old woodwork which made it easy to create real evaluating conditions of functioning gravity ventilation system.

Solar chimneys are superstructures built on the existing ventilating ducts. The difference between them is in materials used to create them. One superstructure, which is 0.47 meter long, 1.75 meter wide and 1.46 meter high, was made of B20 ferroconcrete reinforced every 15 centimeters with rods 10 millimeters in diameter (Fig.2.). The second test stand is a solar chimney made of solid bricks glued together. This superstructure is 0.47 meter long, 1.86 meter wide and 1.45 meter high. Three walls are made of ferroconcrete elements and solid brick. The barrier with south exposure is glazing. It is made of Pilkington Optilam 6,4 safety glass 6.33 millimeters thick, with overall solar energy transmittance of $79 \%$, heat-transfer coefficient of $5.7 \mathrm{~W} /\left(\mathrm{m}^{2} \mathrm{~K}\right)$ and a surface area of, adequately, 1.88 square meter and 2.02 square meters. The walls of solar chimneys are painted black inside and insulated outside with ESP 70-0.037 expanded polystyrene 10 centimeters thick and plastered all over.

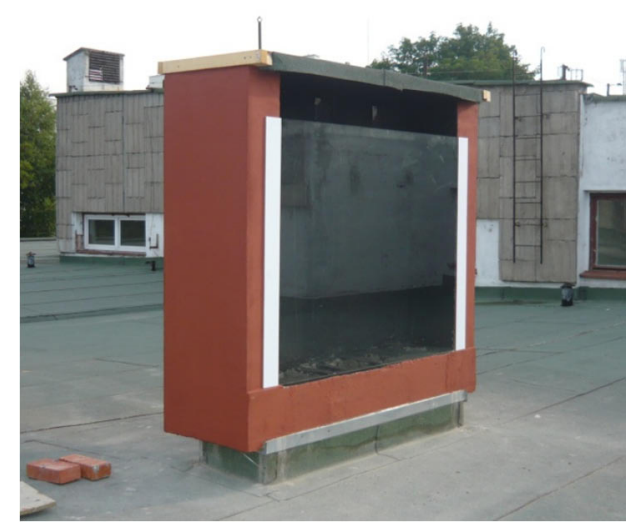

Fig.2. Solar chimney south side 
Materials used to build the walls of a solar chimney were chosen after the analysis of available literature on heat accumulation of building materials. The work [7] confirms the use of ferroconcrete and ceramic brick. This publication presents the results of laboratory research of 10 samples of different materials. It was tested how thermal energy stored in different samples was emitted during cooling down. The samples were put in the drier for three hours with a maximum temperature of $230^{\circ} \mathrm{C}$ inside. Then, the samples were taken out of the drier to take the temperature on their surface for specific time. The results helped to calculate the ability of material to give up stored energy during specific time ( $9000 \mathrm{~s})$. A steel sample gained the highest power - $8.874 \mathrm{~W}$, a concrete sample gained lower 5.3-6.6 W, ceramic brick $-3.72 \mathrm{~W}$ and the lowest was gained by cellular concrete $-1.616 \mathrm{~W}$ and chamotte brick $-2.408 \mathrm{~W}$. It was decided that solar chimneys would be built out of solid ceramic brick and ferroconcrete because of their availability, relatively low price and their popularity in building industry.

\subsection{Methodology of research}

The aim of research that was carried out is the analysis of air flow in the spaces where a solar chimney is one of the elements of a gravity ventilation system. Measurements were taken during windless days in order to eliminate the influence of wind on the results. The first control measurement was taken on the 9-10 July, 2013 before constructing the test stands. The measurement had been being taken for 24 hours with a parameters reading every 2 hours.

When the solar chimneys were built, the measurements were taken in the summer on the following days: 6-7 July, 19-20 July, 9-10 August 2014.

The measurements had been being taken for 24 hours with a parameters reading every 2 hours. The following parameters were measured: the velocity, temperature and humidity of air. The $\mathrm{C} 310$ hytherograph was used to take a relative temperature and humidity and the velocity of air was measured by the TA 430 hot-wire anemometer.

The research was done at two testing points: on the roof, directly at the chimney outlet, and in the rooms, on the outlet grilles of the gravity ventilation system.

The following parameters were measured:

- air velocity at the level of intake grates, at 9 testing points on each of five grates located in the middle of 9 elementary fields resembling a square in shape, which the grate was divided into [8],

- air velocity at the level of the solar chimney outlet, measured at 10 testing points located in the middle of 10 elementary fields, which the grate was divided into [8],

- the temperature and humidity of air inside at specific measuring points that were located in the area where people stayed at 1.2 meter above the floor level,

- the temperature and humidity outdoors.

\subsection{The research results of air flow in a solar chimney}

Figures from 3 to 6 present, in a graphic way, streams of air volume in rooms and at the outlets of chimneys. 


\section{Measurement in the room}

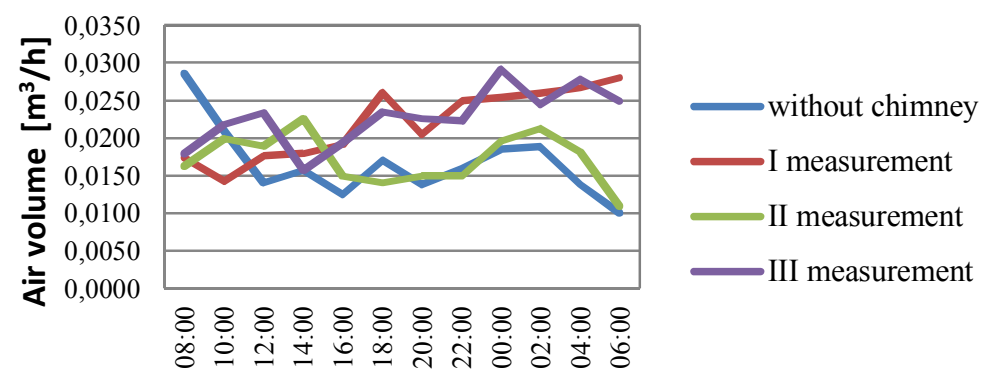

Fig.3. Measurement in the room - solar chimney ferroconcrete

The value of the stream of air volume during twenty-four hours, in each measurement cycle, is changing. These values from 8 a.m. to 4 p.m. indicate little fluctuations from $0.015 \mathrm{~m}^{3} / \mathrm{s}$ to $0.023 \mathrm{~m}^{3} / \mathrm{s}$. This is the time of a direct influence of sunrays on glazing with south exposure. From 4 p.m. to 4 a.m., the values have a growing tendency and after that, they are decreasing. The results obtained from the $1^{\text {st }}$ and $3^{\text {rd }}$ measurement indicate a similarity to the obtained values of the stream of air volume.

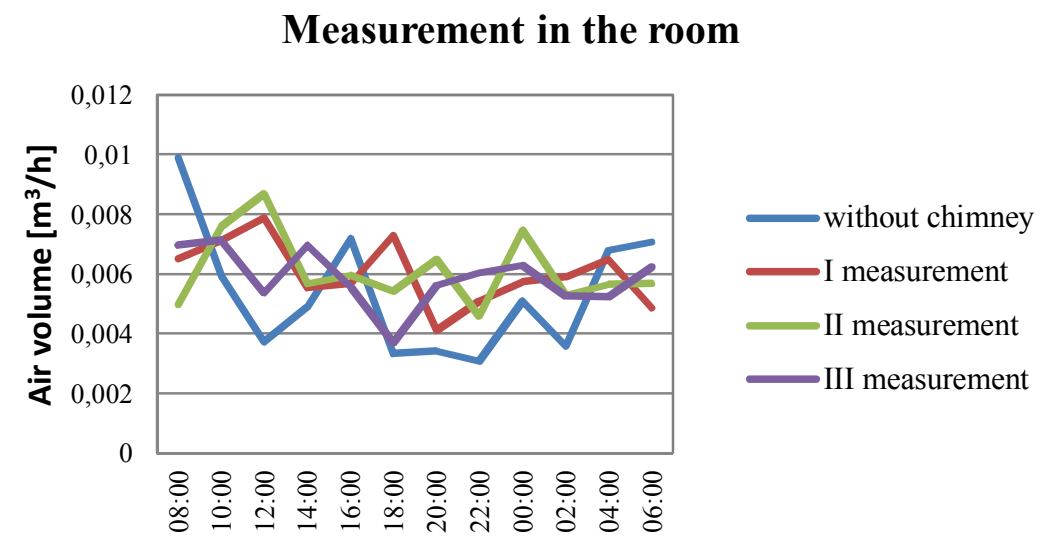

Fig.4. Measurement in the room - solar chimney made of solid bricks

The value of a volume stream during twenty-four hours, in each measurement cycle, is changing. After building a solar chimney, the values are higher, from $0.004 \mathrm{~m}^{3} / \mathrm{s}$ to $0.008 \mathrm{~m}^{3} / \mathrm{s}$. 


\section{Measurement at the outlet of chimney}

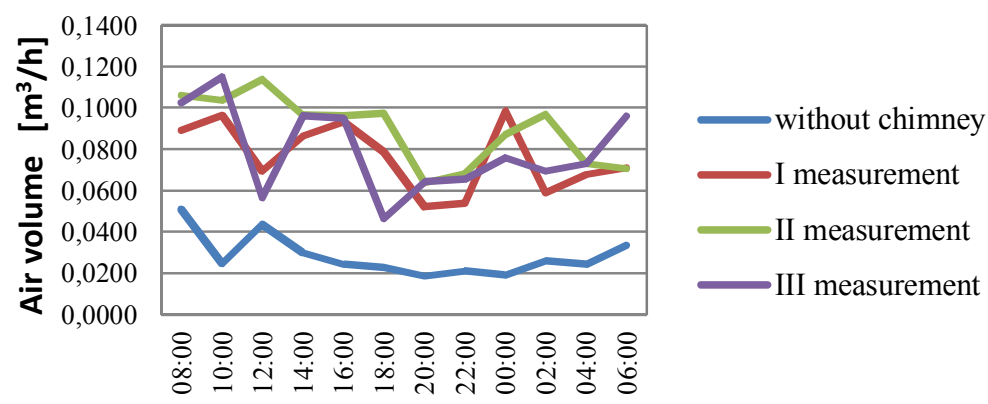

Fig.5. Measurement at the outlet of chimney - solar chimney ferroconcrete

\section{Measurement at the outlet of the chimney}

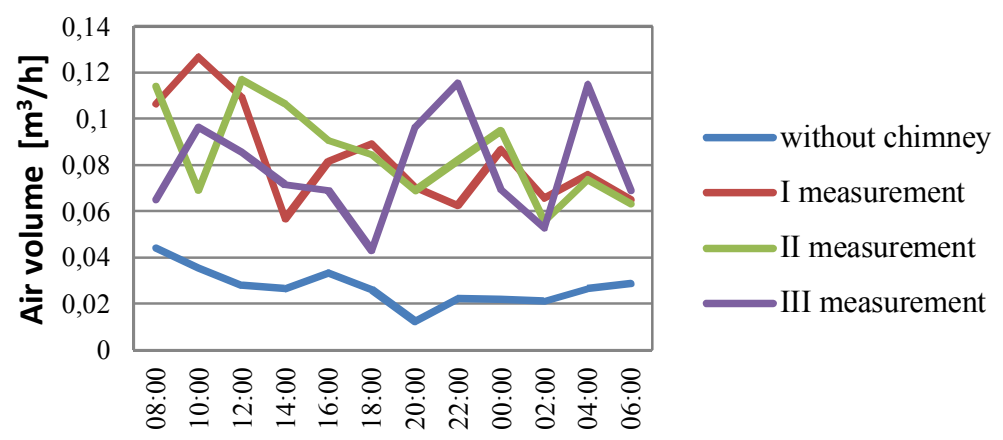

Fig.6. Measurement at the outlet of chimney - solar chimney made of solid bricks

The values of a volume stream at both test stands have clearly increased after building a solar chimney. The values indicate fluctuations from $0.05 \mathrm{~m}^{3} / \mathrm{s}$ to $0.12 \mathrm{~m}^{3} / \mathrm{s}$. Higher values were obtained during a direct impact of sunrays on glazing. From 4 p.m. to 4 a.m., the values of the stream of air volume have a falling tendency.

\section{Summary}

On account of the necessity of limiting the amount of electric energy consumption aiming at cooling down buildings, there is a growing need for introducing alternative solutions in this range.

Solar chimneys are more and more often used elements in building engineering. They use solar energy, acquired at a low cost, in order to improve microclimate indoors. In Poland, the working of a solar chimney as one of the elements of a natural ventilation system has not been examined enough yet. The research presented in this article and carried out at two test stands, illustrates justified use of such a solution. When compared to the situation without a solar chimney, the research shows intensification of air exchange. We can observe the increase in the stream of air volume. It results from intensified air exchange in a room. 


\section{References}

1. PN-B-01411:1999 Wentylacja i Klimatyzacja Terminologia.

2. S. Opaliński, S. Rabczak, Wentylacja grawitacyjna (Oficyna Wydawnicza Politechniki Rzeszowskiej, 2003)

3. A. Pełech, Wentylacja i klimatyzacja: podstawy (Oficyna Wydawnicza Politechniki Wrocławskiej, 2008)

4. R. Khanal, C. Lei, Energy and Buildings 43, 1811-1819 (2011)

5. C. Afonso, A. Oliveira, Energy and Buildings 32, 71-79 (2000)

6. P. Charvat, M. Jicha, J. Stetina, Solar chimney for ventilation and passive cooling. World Renewable Energy Congress VIII, Denver, Colorado USA (2004)

7. B. Zegardło, A. Halicka, 2011. Analiza właściwości cieplnych betonu z kruszywem z odpadów ceramiki sanitarnej. Budownictwo i Architektura 9, 39-49.

8. L. Kołodziejczyk, S. Mańkowski, M. Rubik, Pomiary w inżynierii środowiska (Arkady Warszawa, 1980) 